Article

\title{
Fabrication and Optical Characterization of Polymeric Aspherical Microlens Array Using Hot Embossing Technology
}

\author{
Yanlong Li, Kangsen Li and Feng Gong *
}

check for

updates

Citation: Li, Y.; Li, K.; Gong, F.

Fabrication and Optical

Characterization of Polymeric

Aspherical Microlens Array Using

Hot Embossing Technology. Appl. Sci.

2021, 11, 882. https://doi.org/

10.3390/app11020882

Received: 25 December 2020

Accepted: 13 January 2021

Published: 19 January 2021

Publisher's Note: MDPI stays neutral with regard to jurisdictional claims in published maps and institutional affiliations.

Copyright: (c) 2021 by the authors. Licensee MDPI, Basel, Switzerland. This article is an open access article distributed under the terms and conditions of the Creative Commons Attribution (CC BY) license (https:/ / creativecommons.org/licenses/by/ $4.0 /)$.
Guangdong Provincial Key Laboratory of Micro/Nano Optomechatronics Engineering, College of Mechatronics and Control Engineering, Shenzhen University, Shenzhen 518060, China; 1910293060@email.szu.edu.cn (Y.L.); 1850296001@email.szu.edu.cn (K.L.)

* Correspondence: gongfeng@szu.edu.cn; Tel./Fax: +86-755-26558509

\begin{abstract}
Hot embossing has been widely used in fabricating microlens arrays because of its low cost, high efficiency, and high quality. The process parameters such as molding temperature, molding pressure, and holding temperature affect the microlens array's replication quality. This work selected the stainless steel $\mathrm{S} 136 \mathrm{H}$ tool steel as the mold material to process an aspheric microlens array structure through ultra-precision milling. Polymethyl methacrylate (PMMA) microlens arrays with different surface replication were prepared by controlling the molding temperature, molding pressure, and holding temperature. By analyzing the surface quality, contour replication, and optical imaging of hot-embossed samples, the optimal molding temperature of PMMA for optimal replication of aspheric lens arrays was determined as $130{ }^{\circ} \mathrm{C}$. Besides, the internal elastic recovery of PMMA affected the dimensional accuracy and optical performance of the lens. The results showed that, at the molding pressure of $400 \mathrm{~N}$ and the holding temperature of $60^{\circ} \mathrm{C}$, the surface defects were eliminated, and the aspheric lens array had perfect replication with a profile deviation of only $4 \mu \mathrm{m}$. The aspheric microlens array with good quality was eventually achieved by these optimal process parameters, which provides a foundation for producing aspheric microlens arrays in a low-cost and high-efficiency way.
\end{abstract}

Keywords: hot embossing; aspherical micro lens array; optical imaging; process conditions

\section{Introduction}

The microlens array is an optical device with a micron-sized structure and unique optical characteristics. With high-tech industry development, the microlens array has become an essential element in the optical system owing to its excellent geometric characteristics and optical performance. The microlens array, relying on its small structure, wide field of view, and high resolution, plays an essential role in optical sensing, optical communication, fiber coupling, and non-imaging optics [1]. Microlens arrays can be divided into flat microlens arrays and curved microlens arrays [2]. As a bionic compound eye lens (micro-optical structure inspired by insect eyes), the microlens array plays a significant role in multi-channel imaging and machine vision [3]. It can also be used to design compact imaging systems in medical imaging, monitoring equipment, and other fields [4].

Many studies have focused on manufacturing high-precision, high-quality microlens arrays through different methods, including grinding [5], ultra-precision diamond turning [6], and micro-milling [7]. Although these processing methods can achieve good processing quality, their disadvantages are conspicuous-low efficiency and high processing costs. Recently, new methods have been popular to fabricate microlens arrays such as microinjection molding [8], electrochemical etching [9], local grayscale oxidation [10], direct laser writing [11], photolithography [12], and laser catapulting [13]. Although these new methods can process the microlens array with good surface quality and small element size, they are still challenging for mass production. Some methods require complicated manufacturing processes, such as etching or photolithography technology. Besides, there 
are some problems including complicated processing steps, high cost, and low processing efficiency. Chen et al. [14] and Kirchberg et al. [15] used ultra-precision milling to process silicon-based molds combined with injection molding to process high-quality microlenses, but the processing cycle is too long. Chang et al. [16] realized non-contact rapid rolling on the glass substrate based on the rolling technology and produced a microlens array with high surface quality; however, it is difficult to control each microlens' dimension accuracy. Xie et al. [17] fabricated a polymer refractive microlens array using a stainless steel mold through non-contact hot embossing technology. By contrast, hot embossing has the advantages of low cost, high efficiency, mass production, and environmental friendliness [18-20]. Therefore, hot embossing is considered to be one of the most effective and promising methods for creating optical microlens arrays.

In recent years, many studies on microlens array hot embossing have focused on polymer filling performance, morphology deviation, interface friction and stickiness, geometrical morphology, hot embossing process parameters, birefringence deviation, replication fidelity, and hot-embossing process simulation. Ong et al. [21] used the focused ion beam technology to process microlens cavities on pure nickel, stainless steel, and silicon wafers. Then, they replicated the micro-lens array structure on the polycarbonate surface by hot embossing. The experimental results showed that the silicon wafer array structure processed by the ion beam has an excellent optical surface, so that the lens array replicated by the silicon mold has the optimal quality. Meanwhile, polymer viscosity and hot embossing pressure were the most critical factors for high fidelity and good surface replication.

Zhou et al. [22] used micro-milling technology to process the micro-groove array structure and thermo-forming technology to replicate high-precision polymer micro-arch array lenses. Zhang et al. [23] used induction heating to achieve effective hot embossing of polymer array structures on silicon-based molds. The experimental results showed that rapid local-induction hot press forming technology can improve replication and morphology replication. Wang et al. [24] studied the springback behavior of thermoplastic polymers during hot embossing. Polymers above the glass transition temperature fill the cavity more easily owing to enhanced flow characteristics. However, the polymer can produce large springback deformation during the cooling stage, which distorts the profile replication. Moreover, springback deformation can be avoided by increasing the processing time or the hot embossing temperature.

Li et al. [25] studied the structure replication of Polymethyl methacrylate (PMMA) microlens array during non-contact hot embossing. The surface tension during the forming process affected the profile replication of the lens and could be achieved by controlling the process conditions. The above research shows that, by adjusting the process parameters above the transition temperature, the polymer can be hot-pressed to form optical structures with high-quality and high-precision. However, many studies focus on the manufacturing process and forming characteristics of the lens array instead of on the lens's optical performance after forming.

Therefore, the work analyzed the focusing and imaging of the manufactured aspheric lens array. Firstly, the mold with an aspherical array structure was obtained by ultraprecision milling. The hot embossing experiment was then performed on the precision mold using the precision molding machine to prepare a series of microlens arrays with different geometric characteristics by adjusting the process parameters. The replication characteristics of the aspheric microlens array, including surface quality and surface profile replication, were analyzed. Finally, the optical imaging platform was established for optical experiments, thereby investigating the influence of process parameters on the lens's optical performance and summarizing the variation of microlens topography quality under different process conditions. 


\section{Materials and Methods}

\subsection{Materials}

PMMA is a commonly used optical material with good optical properties, such as high transparency, high transmittance, ideal refractive index, and low refractive index dispersion. Moreover, its low cost and good mechanical processability make it more popular in optical devices. The deformation temperature and glass transition temperature of PMMA are 90 and $104{ }^{\circ} \mathrm{C}$, respectively. The melting temperature is $220^{\circ} \mathrm{C}$ (much lower than that of optical glass), suitable for precision processing and molding.

The work used PMMA as the micro-hot pressing material. Table 1 shows PMMA materials' properties, such as thermal expansion coefficient, specific heat, and refractive index. Besides, PMMA was a glassy polymer at room temperatures, with PMMA balls with a diameter of $6 \mathrm{~mm}$ used.

Table 1. Physical properties of PMMA and S136H die steel.

\begin{tabular}{ccc}
\hline Property & PMMA & S136H \\
\hline Young's Modulus $(\mathrm{GPa})$ & 2.4 & 220 \\
Poisson ratio & 0.37 & 0.2 \\
Density $\left(\mathrm{kg} / \mathrm{m}^{3}\right)$ & 1185 & 7850 \\
Thermal conductivity $\left(\mathrm{W} / \mathrm{m}^{2} \cdot \mathrm{K}\right)$ & 0.2 & 16.5 \\
Specific heat $(\mathrm{J} / \mathrm{kg} \cdot \mathrm{K})$ & 1466 & 461 \\
Thermal expansion $\left(\mathrm{K}^{-1}\right)$ & $4.4 \times 10^{-4}$ & $11 \times 10^{-6}$ \\
Glass transition temperature $\left({ }^{\circ} \mathrm{C}\right)$ & 105 & \\
Melting temperature $\left({ }^{\circ} \mathrm{C}\right)$ & 220 & \\
\hline
\end{tabular}

In the hot embossing process, the mold material is critical to the final embossed optical elements' quality. The selected mold material must withstand a high temperature and oxidation and hardly have any deformation during compression at high temperatures. Besides, a suitable mold material should enable microstructures to be processed on its surface. stainless steel S136H steel (wt\%: Cr (13.6\%), C (0.38\%), P (<0.03\%), S (<0.03\%), Mn $(0.5 \%)$, Si $(0.8 \%))$ is a high-purity, mirror-finish material with good polishing performance, excellent rust and acid resistance, and less heat treatment deformation. It is suitable as a mold for making optical devices (high-finish surfaces) with Complementary metal oxide semicond (PVC), Polypropylene (PP), Epoxide resin (EP), Polycarbonate (PC), PMMA, and other materials. Meanwhile, it meets the production requirements of low cost and high quality. Therefore, $\mathrm{S} 136 \mathrm{H}$ mold steel was adopted in the experiment.

\subsection{Mold Design and Processing}

Compared with spherical elements, aspheric optical elements have a unique curvature radius to achieve improved optical performance. They can correct spherical aberration, improve imaging resolution, reduce lenses in lens modules, and miniaturize the lens. By adjusting the surface constant and aspheric coefficients, the spherical aberration caused by the spherical lens can be eliminated to the greatest extent. The profile of the aspheric lens is expressed as

$$
\begin{gathered}
Z=\frac{c S^{2}}{1+\sqrt{1-(K+1) c S^{2}}}+A S^{4}+B S^{6}+C S^{8}+D S^{10}+E S^{12}+F S^{14}+G S^{16} \\
c=1 / r, S^{2}=x^{2}+y^{2}
\end{gathered}
$$

The profile of a $10 \times 10$ aspheric microlens array mold is designed by MATLAB software, along with the schematic diagram and parameter values (see Figure 1a). The aspheric coefficients are as follows: $\mathrm{K}=-0.4133338, \mathrm{~A}=0, \mathrm{~B}=-0.0121199, \mathrm{C}=-0.39822027$, $\mathrm{D}=1.0637157, \mathrm{E}=-3.06126374, \mathrm{~F}=4.7284994, \mathrm{G}=-3.50416555$, and the diameter of $\mathrm{a}$ single lens is $0.84 \mathrm{~mm}$. 

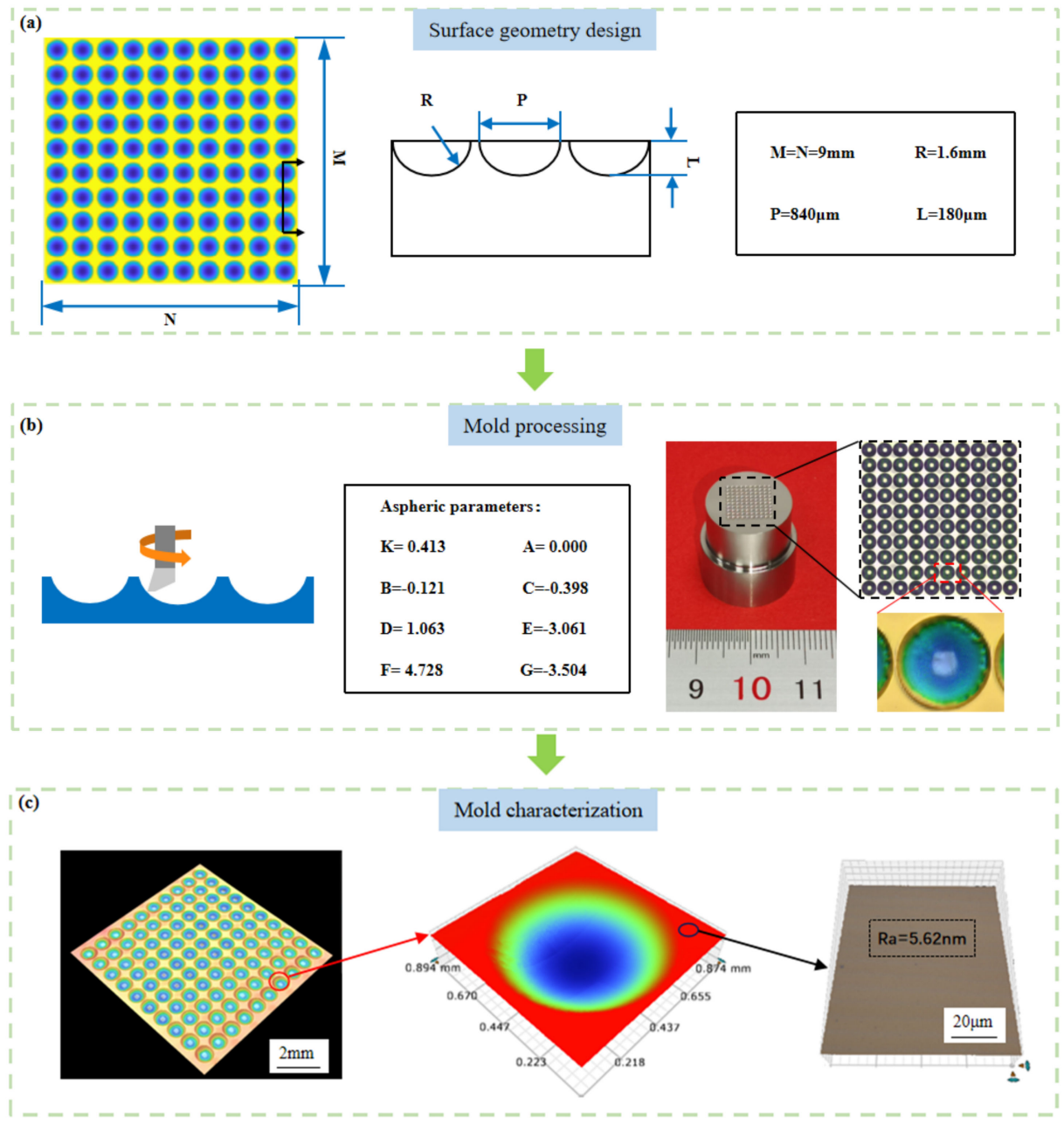

Figure 1. Aspheric microlens array mold design and processing. (a) Design of aspheric microlens array with basic geometric parameters, (b) mold processing, and (c) characterization of microlens array mold.

$\mathrm{S} 136 \mathrm{H}$ tool steel was used as the mold material, and single-point precision turning was prone to tool wear when carbon-based metals were machined. Therefore, we used Toshiba ultra-precision processing machine UVM-450C (Tokyo, Japan) to micro-mill the mold surface and process the microstructure on the mold surface. Then, the work employed optical mold polishing center with grinding and optical polishing technology to machine the mold, thereby improving the mold end surface's smoothness and reducing the surface roughness.

Figure 1 shows the shape design, manufacturing, and characterization process of the microlens array mold. The mold surface was characterized to verify the mold processing accuracy (See Figure 1c). The overall three-dimensional surface captured by a laser confocal microscope was used to measure multiple locations' local surface quality under a white light interferometer. Through the surface measurement of the white light interferometer, the measurement results indicate that the surface average Sa was $5.62 \mathrm{~nm}$.

\subsection{Hot Embossing of the Microlens Array}

The hot embossing process included presetting, heating, embossing, cooling, and demolding (See Figure 2). We used SZU's PGMM30 glass molding machine (Shenzhen, China) (See Figure 3) to complete the molding process. It basically consists of five subsystems including the moulding machine, vacuum system, nitrogen system, cooling water, and control system. First, the mold and sleeves were pre-fixed on the platform, and the 
dust-free PMMA ball was carefully placed at the center of the $10 \times 10$ array mold. Then, the lower mold was manually servo-positioned upwards to leave a gap of 1-3 $\mathrm{mm}$ between the upper mold and PMMA and moved upwards with a smaller torque force and speed $(100 \mathrm{~N}$ and $10 \mathrm{~mm} / \mathrm{s})$ through the torque positioning of the lower mold until its position was no longer changing. Next, the PMMA ball was heated (SZU's PGMM30 transfers heat to the upper and lower molds through infrared induction heating. Then it is connected to the control system through the temperature sensor to form a controllable closed loop system to set the mold temperature.) and the lower mold was compressed by a constant pressure between 300 and $500 \mathrm{~N}$. When the PMMA ball was in a viscoelastic state, it could deform easily so that the filling process could be achieved within time with the lower mold in the proper position. After hot embossing, the PMMA was held at a holding pressure of $200 \mathrm{~N}$, and the holding pressure was removed at $50-90^{\circ} \mathrm{C}$. Finally, demolding could be performed at room temperature.

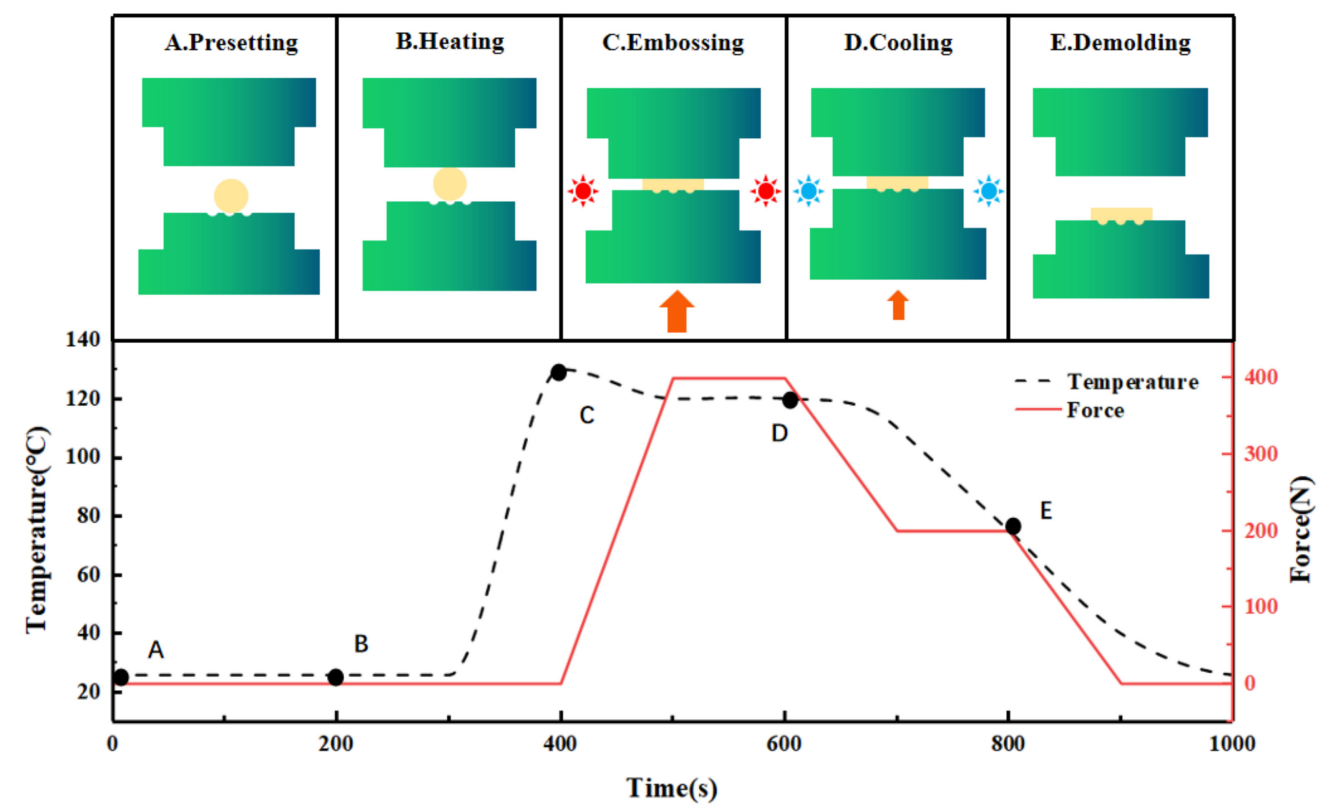

Figure 2. Process diagram of hot press forming and time history of force and temperature.

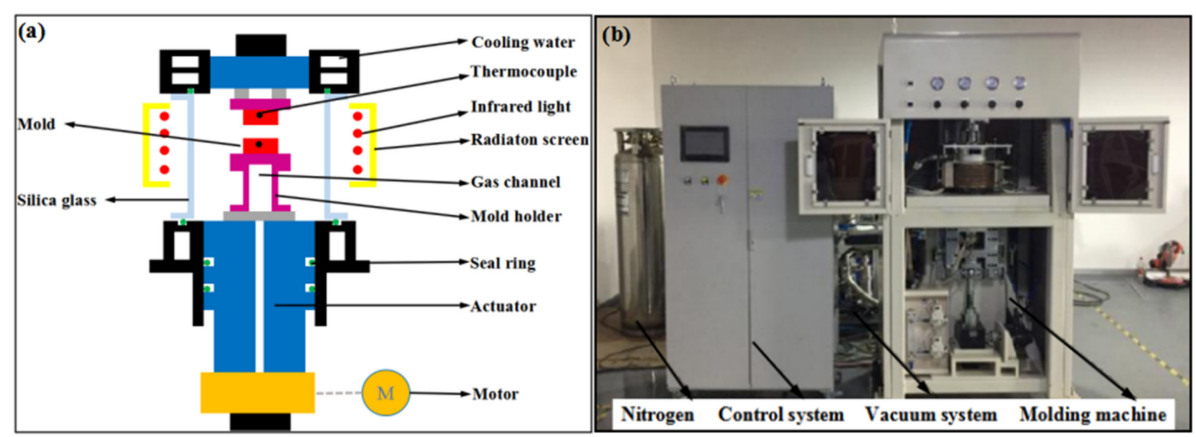

Figure 3. (a) Schematic diagram of molding machine system and (b) SZU's PGMM30.

During the hot embossing process, process parameters such as compressing temperature, compressing pressure, holding temperature, holding pressure, and cooling rate greatly influence the deformation behavior and replication quality of the hot-embossing microstructure. Thus, we designed an orthogonal experiment to investigate the effect of hot-pressing temperature, hot-pressing pressure, and holding temperature on microstructures.

The temperature range in the work was set according to the flow behavior of PMMA during the hot embossing process. At about $104{ }^{\circ} \mathrm{C}$, PMMA changes from the glass state 
to the elastic rubber state, in which state plastic flow does not exist because the memory effect of the thermoplastic polymer makes it challenging to maintain the formed shape. Above $120{ }^{\circ} \mathrm{C}$, PMMA is in a typical viscoelastic state, a plastic state, which exhibits viscoelasticity and plastic flow. It is an appropriate state for hot embossing [26]. Therefore, the temperature range was set as $110-150{ }^{\circ} \mathrm{C}$. In the experiment, at the lowest molding temperature of $110^{\circ} \mathrm{C}$, holding temperature of $80^{\circ} \mathrm{C}$, and hot-pressing pressure of $300 \mathrm{~N}$, the microlens structure with the basic replicated morphology could be processed. Table 2 shows the final range of process parameters.

Table 2. Molding test process parameters.

\begin{tabular}{cccc}
\hline \multirow{2}{*}{ Levels } & \multicolumn{3}{c}{ Factors } \\
\cline { 2 - 4 } & Embossing Temperature $\left({ }^{\circ} \mathbf{C}\right)$ & Embossing Force (N) & Holding Time (s) \\
\hline 1 & 110 & 300 & 50 \\
2 & 130 & 400 & 70 \\
3 & 150 & 500 & 90 \\
\hline
\end{tabular}

\section{Results and Discussion}

\subsection{Influence of Different Process Parameters on MLA}

\subsubsection{Molding Temperature}

Molding temperature is one of the most critical parameters of the molding process. The glass transition point temperature $\mathrm{Tg}$ of PMMA is $104{ }^{\circ} \mathrm{C}$. When it is lower than the Tg point, PMMA is glassy with extensive elastic recovery and weak deformability. The temperature must be kept constant during the hot embossing because any temperature change will affect the polymer substrate's fluid resistance, resulting in pattern defects [27].

In the preliminary experiment, we fabricated the microlens when the hot embossing temperature was lower than $\mathrm{Tg}$. At the molding temperature of $100{ }^{\circ} \mathrm{C}$, molding pressure of $400 \mathrm{~N}$, and holding temperature of $70^{\circ} \mathrm{C}$ (See Figure $4 \mathrm{a}$ ), PMMA could not be filled into the mold, resulting in an incomplete structure of the copied microlens array. The contour of the microlens array measured by the confocal laser microscope was used to analyze contour replication.

Figure $4 \mathrm{~b}$ shows a comparison between the microlens contour and the mold contour. The contours of the lens and the mold are very different. When the temperature is lower than the glass transition temperature, the deformation of PMMA is limited and the elastic recovery is extensive, so it is difficult to obtain a designed aspheric lens below the transition temperature. The minimum hot-embossing temperature needs to be higher than the glass transition point temperature of PMMA $\left(104^{\circ} \mathrm{C}\right)$. When the molding temperature is higher than the glass transition temperature $\mathrm{Tg}$, PMMA is in a viscoelastic state with large deformation and small elastic recovery.

Figure $4 \mathrm{c}$ shows the molded aspheric lens profile with the molding temperature of $110{ }^{\circ} \mathrm{C}$, molding pressure of $400 \mathrm{~N}$, and holding temperature of $70{ }^{\circ} \mathrm{C}$. The contour of the molded aspheric lens coincides with the contour of the mold. With the increased temperature, the viscosity and flow deformation ability of PMMA gradually increase. Therefore, under the same conditions, as the molding temperature increases, better fluidity and higher profile replication will be achieved. When the molding temperature is $130{ }^{\circ} \mathrm{C}$, the maximum deviation between the lens profile and the molding profile is about $4 \mu \mathrm{m}$.

However, when the temperature is higher than a certain range threshold (see Figure $4 \mathrm{e}$ ), bubbles will be generated inside the PMMA. They will react quickly with the mold surface, thereby affecting the surface quality of the microlens. When the temperature is too high, a massive change in the cooling phase's temperature will result in a low surface finish of the replicated lens. At high molding temperatures, the PMMA surface adheres and falls off as a result of the damaging effect, which affects the lens's surface roughness. Therefore, according to the above analysis, it is advantageous to have a temperature slightly higher than $\mathrm{Tg}$, because lower viscosity and higher fluidity facilitate the molding process. However, a 
too high temperature causes PMMA to stick to the mold, and massive cooling temperature changes cause low surface finish and bubbles.
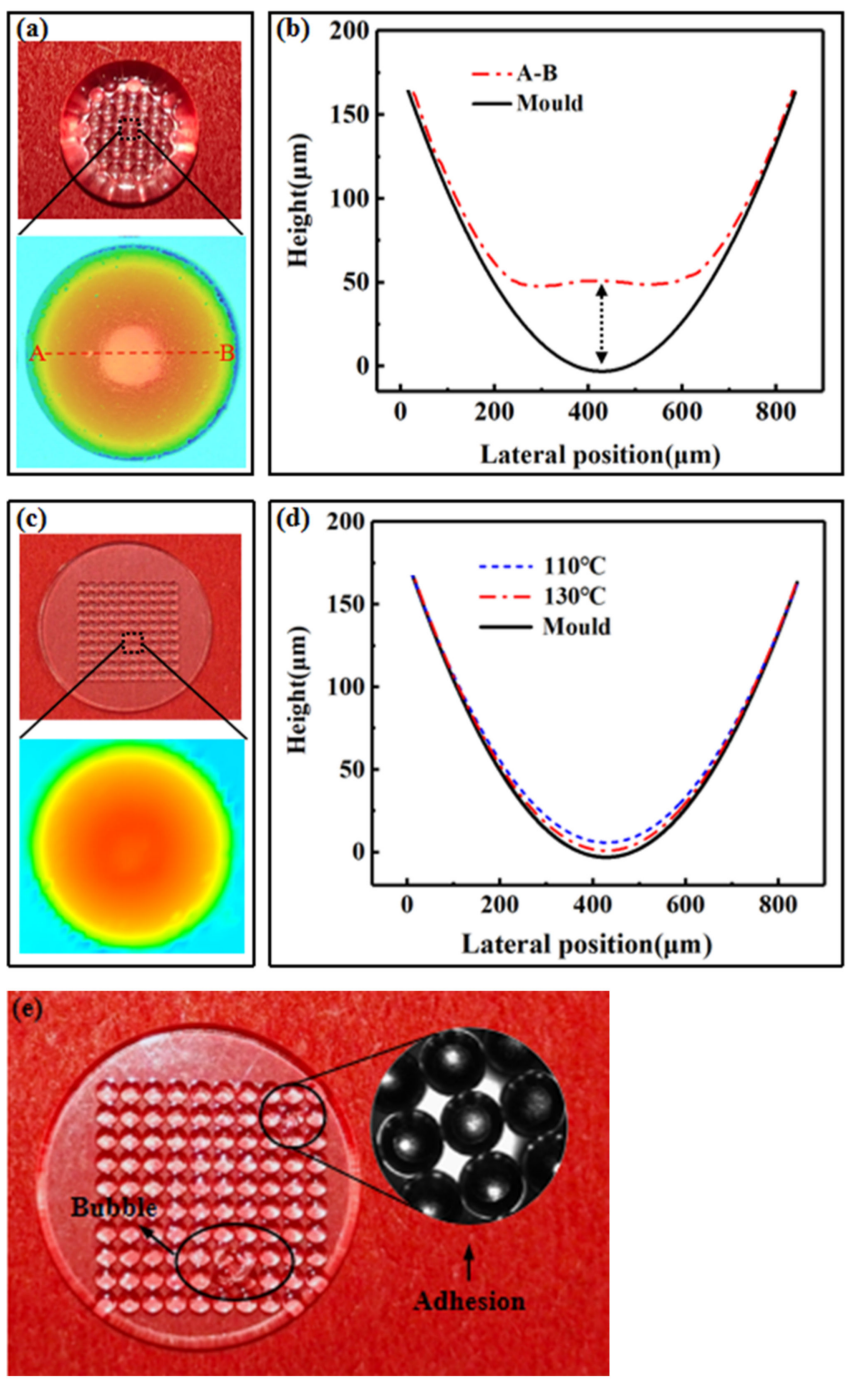

Figure 4. (a) Aspheric microlens array image at a molding temperature of $100{ }^{\circ} \mathrm{C},(\mathbf{b})$ the comparison of aspheric microlens profile and mold profile at a molding temperature of $100{ }^{\circ} \mathrm{C}$, (c) aspheric microlens array image when the temperature is $130{ }^{\circ} \mathrm{C},(\mathbf{d})$ the comparison of the aspheric microlens profile and mold profile when the molding temperature is $110^{\circ} \mathrm{C} / 130{ }^{\circ} \mathrm{C}$, and (e) the surface of the aspheric microlens array with bubbles when the molding temperature is $150{ }^{\circ} \mathrm{C}$.

\subsubsection{Holding Temperature}

When the pressing process is over, it will immediately enter the holding pressure process (applying a constant pressure of $200 \mathrm{~N}$ to hold the pressure until the mold temperature drops to the specified holding pressure-temperature). The holding temperature is also one of the main factors affecting the quality of the lens. The lower holding temperature means the microlens array experiences a longer holding time. Therefore, the microlens array's return deformation reduces. With the molding temperature of $130^{\circ} \mathrm{C}$, molding pressure of $400 \mathrm{~N}$, and holding temperature of $90^{\circ} \mathrm{C}$, PMMA is observed to have elastic recovery and shrinkage after removing the holding pressure during cooling and demolding.

Figure 5 a shows the lens forming profile at the holding temperature of $90{ }^{\circ} \mathrm{C}$. As the holding temperature decreases, the elastic recovery of PMMA is eliminated, with the defects of the aspheric lens array reduced, which means the forming quality is improved. Figure $5 \mathrm{~b}$ shows the copied curve of the lens profile at the holding temperature of 70 and 
$50{ }^{\circ} \mathrm{C}$. When the holding temperature drops from 90 to $50{ }^{\circ} \mathrm{C}$, the sample's surface quality is significantly improved. Simultaneously, by observing the aspheric microlens array with magnification, at the holding temperature of $90^{\circ} \mathrm{C}$, the PMMA interface's adhesion and the elastic recovery deformation of the material affect the morphology and imaging effect of the microlens. As the holding temperature decreases and the holding time increases, the microlens' surface morphology becomes better (See Figure 5c).
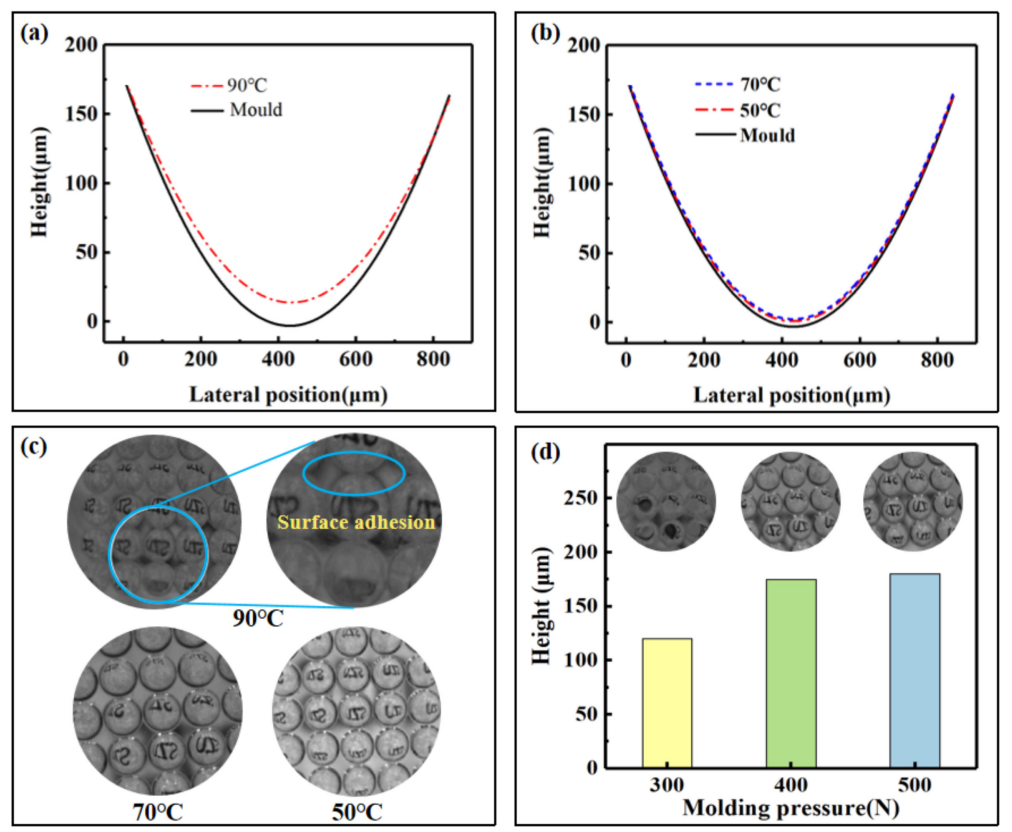

Figure 5. (a) Comparison of aspheric lens profile and mold profile when the holding temperature is $90{ }^{\circ} \mathrm{C}$; (b) comparison of aspheric lens profile and mold profile when the holding temperature is $70{ }^{\circ} \mathrm{C}$ and $50{ }^{\circ} \mathrm{C}$; (c) the surface and imaging performance of aspheric microlens at holding temperatures of $90{ }^{\circ} \mathrm{C}, 70{ }^{\circ} \mathrm{C}$, and $50{ }^{\circ} \mathrm{C}$; and (d) the heights and surface morphologies of the aspheric lens under different molding pressures.

\subsubsection{Molding Pressure}

Molding pressure is one of the critical factors affecting the surface quality of the lens. Figure $5 \mathrm{~d}$ shows the height of the aspheric lens under different molding pressures at the molding temperature of $130{ }^{\circ} \mathrm{C}$ and holding temperature of $70^{\circ} \mathrm{C}$. When the embossing force is 300,400 , and $500 \mathrm{~N}$, the thicknesses of the micro lens we measured are 1.05, 0.91, and $0.83 \mathrm{~mm}$, and the diameters are $12.05,13.22$, and $14.51 \mathrm{~mm}$, respectively. Furthermore, we can estimate that the average molding pressures on the sample surface are $2.7 \times 10^{6}$, $3.0 \times 10^{6}$, and $3.3 \times 10^{6} \mathrm{~Pa}$. This is positively related to the applied embossing force. As the molding pressure increases, the degree of replication of the lens increases; however, when the pressure is greater than a specific value, the lens's profile height hardly changes because PMMA has filled the entire cavity. If the molding pressure is too small, the aspheric lens cannot be filled, affecting image quality. However, if the molding pressure is too high, it will cause the mold to be easily worn and indirectly affect the surface quality.

\subsection{Characterization and Replication of Microlens Array}

According to the optimal process parameters obtained above, a set of process parameters (hot embossing pressure of $400 \mathrm{~N}$, hot embossing temperature of $130{ }^{\circ} \mathrm{C}$, and holding embossing temperature of $50^{\circ} \mathrm{C}$ ) were selected to compress PMMA balls. A local $3 \times 3$ MLA (microlens array) area of the lens array was characterized by the laser confocal microscope equipment to show good surface quality.

Figure $6 \mathrm{a}, \mathrm{b}$ show the surface morphologies of $3 \times 3$ MLA features on the mold end face and MLA replicas, respectively. The copied MLA meets the requirements of shape 
accuracy and surface finish. However, the local microlens' surface finish is not sound (for example, insufficient filling and undulations were discovered on the top of the aspheric surface) because of the low local surface quality of the mold or the surface defects caused by the adhesion between mold and PMMA during demolding. Surface defects can be solved by adding suitable coatings on the mold surface in subsequent research. Simultaneously, the measurement error caused by external noise interference during the laser confocal microscope measurement should be considered.

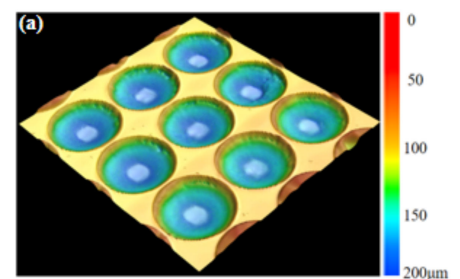

(c)

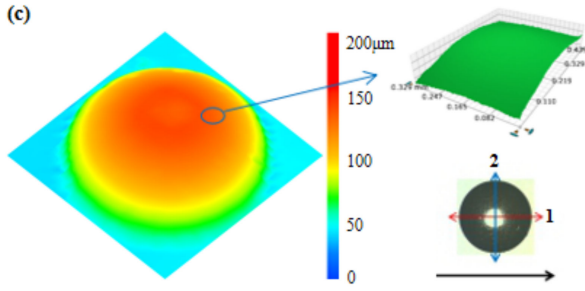

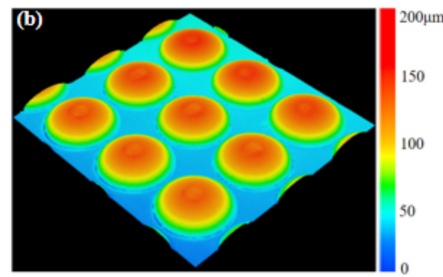

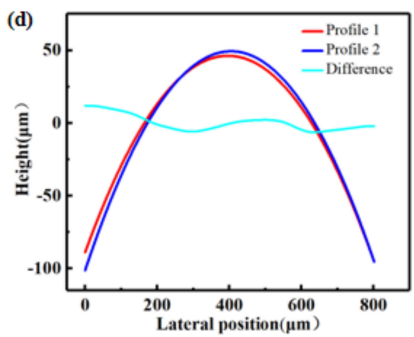

Figure 6. (a) $3 \times 3$ MLA characterization of the mold, (b) $3 \times 3$ MLA characterization of the sample, (c) the original measurement surface, and (d) the profile and error of the two radial cross-section surfaces.

Further shape characterization analysis is performed on a single local MLA, and the surface profile data extracted from the two perpendicular cross-sections in Figure 6c are compared in Figure 6d. The contours are in right consistency, proving that the MLA has good axial symmetry.

\subsection{Optical Imaging Experiment}

An optical imaging experiment was designed to evaluate the focusing and imaging of the microlens array. First, optical simulation software ZEMAX was used to design and simulate a $10 \times 10$ microlens array's light path. Figure 7 a shows that a combination of point light sources and single convex lenses is used to form a parallel light source. After the parallel light passes through the microlenses, a $10 \times 10$ array of focused spots is formed on the screen. Figure $7 \mathrm{~b}, \mathrm{c}$ show that the aspheric microlens array has excellent focusing performance for parallel light. As the point light source obtains the parallel light, the imaged light intensity on the screen will fluctuate owing the $X$ coordinate axis change (See Figure 7d).

Based on the mentioned ZEMAX optical simulation model, a platform for optical imaging experiments was established. Figure 8a shows aspherical-array optical imaging, including A (light source controller), B (parallel light source device), C (aspheric lens array), $\mathrm{D}$ (magnifying lens), E (complementary metal oxide semicond (CMOS) camera), and F (screen). The light source controller drives parallel light sources to achieve a constant current control with a high pulse width modulation (PWM) frequency, suppressing the light source flicker and ensuring stable light emission. Through the control software, the light source can realize 256-level brightness adjustment and channel switching. Besides, the parallel light source's beam diameter is $30 \mathrm{~mm}$, and the flatness is less than 0.1 . The camera is a CMOS camera with 25,921,944 pixels, a $15 \mathrm{fps}$ frame rate, and black and white pigments. The centering holder can adjust angles and positions. The imaging system includes a target (a screen with a capital letter " $\mathrm{A}$ ") and a PMMA sample on a rotating table. During the measurement, the black capital letter " $\mathrm{A}$ " is projected through the PMMA microlens array, 
and each microlens can form tiny and clear " $\mathrm{A}$ " images on the charge coupled device (CCD) camera (See Figure $8 b$ ). The produced microlenses have good imaging performance.

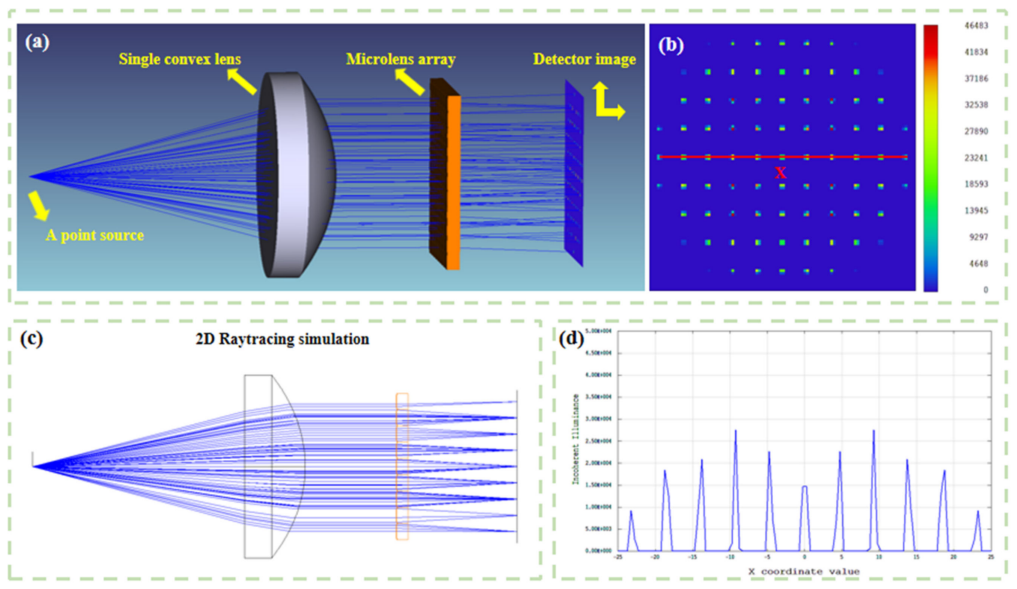

Figure 7. Simulation of optical imaging. (a) Three-dimensional schematic diagram of optical simulation, (b) simulated light focusing points on the receiver, (c) planar ray tracing simulation, and (d) light intensity distribution of the receiver $x$ section.

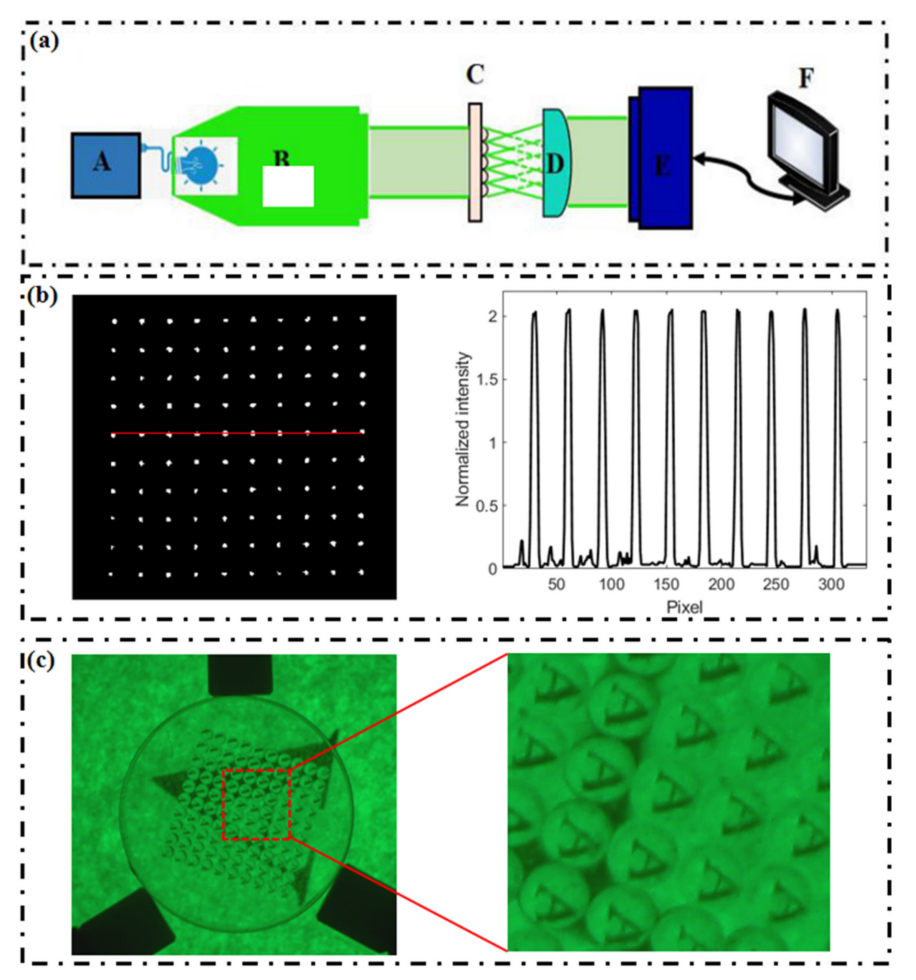

Figure 8. (a) The schematic diagram of optical imaging platform, (b) focus imaging and intensity data captured by CCD camera of PMMA microlens array, and (c) the capital letter "A" focused on the aspheric lens array.

Moreover, the focusing function of the micro lens array was also tested. As shown in Figure $8 c$, a parallel beam is projected onto the PMMA microlens array, and the focus image is obtained by adjusting the distance. To evaluate the uniformity of light spots, a random line with 10 spots was selected and the light intensity of each spot was calculated. It can be seen that the manufactured PMMA compound eye lens has perfect focusing function and uniform light spot intensity. 


\section{Conclusions}

The work used an ultra-precision milling process to machine a microlens array mold with an aspheric structure, and then a PMMA aspheric lens array was produced by compression molding technology. The profile replications and surface qualities of the lenses under different process parameters were analyzed, and an optical imaging platform was established to evaluate the imaging performance of the aspheric lens array.

(1) The molding temperature affected the final contour of the lens. When the temperature was lower than the Tg point, the deformation resistance of PMMA was too large to achieve sufficient deformation. Meanwhile, uneven internal-stress distribution affected the optical performance. Experiments showed that, at the molding temperature of $130{ }^{\circ} \mathrm{C}$, the aspheric lens array could obtain better profile replication and surface quality (compared with the microlens at $110{ }^{\circ} \mathrm{C}$, the filling degree is increased by $40 \%$ ) and the optimal optical imaging performance. However, when the temperature exceeded $150{ }^{\circ} \mathrm{C}$, obvious bubbles were generated inside the lens, which adversely affected the lens formation and imaging properties.

(2) As the holding temperature decreased, the elastic recovery of PMMA became weaker. When the holding temperature was close to the Tg point, elastic recovery occurred inside the material at room temperatures, which affected the surface quality and contour fidelity. At the holding temperature of $50^{\circ} \mathrm{C}$, the aspheric lens array could achieve perfect profile replication with the molding defects, eliminating the optical imaging performance.

(3) The molding pressure had the least significant effect on the lens profile's fidelity. By optimizing the molding pressure value, the filling degree was increased by $31 \%$. When the molding pressure was greater than a certain threshold, the lens profile replication remained unchanged. The three process parameters-molding temperature, holding temperature, and molding pressure — significantly affected the forming quality and optical imaging.

Author Contributions: Conceptualization, F.G. and Y.L.; Methodology, F.G., and K.L.; Software, Y.L.; Writing-Original Draft Preparation, Y.L. and K.L.; Funding Acquisition, F.G. All authors have read and agreed to the published version of the manuscript.

Funding: The authors gratefully acknowledge the financial support of the Natural Science Foundation of Guangdong Province (2018A030313466) and the Shenzhen Science and Technology Innovation Commission (SGDX20190919094403772).

Institutional Review Board Statement: Not applicable.

Informed Consent Statement: Not applicable.

Data Availability Statement: Data is contained within the article.

Acknowledgments: The author would like to appreciate the colleagues and advisor for their help to improve the paper.

Conflicts of Interest: The authors declare no conflict of interest.

\section{References}

1. Chronis, N.; Liu, L.G.; Jeong, K.-H.; Lee, L.P. Tunable liquid-filled microlens array integrated with microfluidic network. Opt. Express 2003, 11, 2370-2377. [CrossRef]

2. Zhang, H.; Yi, A.Y.; Li, L.; McCRAY, D.L.; Sebastian, S.; Naples, N.J.; Gebhardt, A.; Risse, S.; Eberhardt, R.; Tunnermann, A. Development of a low cost high precision three-layer 3D artificial compound eye. Opt. Express 2013, 21, 22232-22245. [CrossRef] [PubMed]

3. Chen, J.W.; Cheng, J.Y.; Zhang, D.P.; Chen, S.-C. Precision UV imprinting system for parallel fabrication of large-area micro-lens arrays on non-planar surfaces. Precis. Eng.-J. Int. Soc. Precis. Eng. Nanotechnol. 2016, 44, 70-74. [CrossRef]

4. Chen, X.L.; Qu, N.S.; Li, H.S.; Xu, Z.Y. Pulsed electrochemical micromachining for generating micro-dimple arrays on a cylindrical surface with a flexible mask. Appl. Surf. Sci. 2015, 343, 141-147. [CrossRef] 
5. Yan, G.P.; Zhang, Y.; You, K.Y.; Li, Z.X.; Yuan, Y.K.; Fang, F.Z. Off-spindle-axis spiral grinding of aspheric microlens array mold inserts. Opt. Express 2019, 27, 10873-10889. [CrossRef]

6. Liu, X.L.; Zhang, X.D.; Fnag, F.Z.; Zeng, Z.; Gao, H.M.; Hu, X.T. Influence of machining errors on form errors of microlens arrays in ultra-precision turning. Precis. Eng.-J. Int. Soc. Precis. Eng. Nanotechnol. 2015, 96, 80-93. [CrossRef]

7. McCall, B.; Tkaczyk, T.; Birch, G.; Descour, M. Fabrication of plastic microlens arrays for array microscopy by diamond milling techniques. In Proceedings of the Micromachining and Microfabrication Process Technology XV, San Francisco, CA, USA, 16 February 2010; p. 75900A.

8. Zhang, X.D.; Fang, F.Z.; Li, L.H.; Li, Z.X.; Chan, C.Y.; Zhu, L.L.; Lee, W.B. Highly uniform manufacturing method for large-area microlens arrays. Int. J. Adv. Manuf. Technol. 2017, 95, 99-108. [CrossRef]

9. Lai, L.-J.; Zhou, H.; Zhu, L.-M. Fabrication of microlens array on silicon surface using electrochemical wet stamping technique. Appl. Surf. Sci. 2016, 364, 442-445. [CrossRef]

10. Chen, C.-F.; Gwo, S.; Tzeng, S.-D.; Chen, H.-Y. Silicon microlens structures fabricated by scanning-probe gray-scale oxidation. Appl. Surf. Sci. 2005, 30, 652-654. [CrossRef]

11. Delgado, T.; Nieto, D.; Flores-Arias, M.T. Fabrication of microlens arrays on soda-lime glass using a laser direct-write technique and a thermal treatment assisted by a CO2 laser. Opt. Lasers Eng. 2015, 73, 1-6. [CrossRef]

12. Chou, M.-C.; Wu, S.-T.; Pan, C.T.; Shen, S.C.; Chen, M.-F.; Lin, K.L. A novel method to fabricate gapless hexagonal micro-lens array. Sens. Actuator A-Phys. 2005, 118, 298-306. [CrossRef]

13. Surdo, S.; Duocastella, M.; Carzino, R.; Diaspro, A. Single-shot laser additive manufacturing of high fill-factor microlens arrays. Adv. Opt. Mater. 2018, 6, 1701190. [CrossRef]

14. Chen, L.; Sun, L.-L.; Kirchberg, S.; Jiang, B.-Y.; Xie, L.; Jia, Y.-L. Fabrication of long-focal-length plano-convex microlens array by combining the micro-milling and injection molding processes. Appl. Opt. 2014, 53, 7369-7380. [CrossRef] [PubMed]

15. Kirchberg, S.; Chen, L.; Xie, L.; Ziegmann, G.; Jiang, B.; Riemer, K.; Riemer, O. Replication of precise polymeric microlens arrays combining ultra-precision diamond ball-end milling and micro injection molding. Microsyst. Technol. 2012, 18, 459-465. [CrossRef]

16. Chang, C.Y.; Yang, S.Y.; Sheh, J.L. A roller embossing process for rapid fabrication of microlens arrays on glass substrates. Microsyst. Technol. 2006, 12, 754-759. [CrossRef]

17. Xie, D.; Liu, Y.X.; Chang, X.F.; Shu, X.Y.; Wang, Y.C.; Ding, H.Q. Rapid fabrication of thermoplastic polymer refractive microlens array using contactless hot embossing technology. Opt. Express 2015, 23, 5154-5166. [CrossRef]

18. Chang, C.-Y.; Yu, C.-H. A basic experimental study of ultrasonic assisted hot embossing process for rapid fabrication of microlens arrays. J. Micromech. Microeng. 2015, 25, 025010. [CrossRef]

19. Lin, C.R.; Hung, C. Preventing non-uniform shrinkage in open-die hot embossing of PMMA microstructures. J. Mater. Process. Technol. 2003, 140, 173-178. [CrossRef]

20. Liu, X.H.; Yi, A.Y.; Zhou, T.F.; Zhang, L.; Zhou, W.C.; Yu, J.F.; Lee, L.J. Fabrication of spherical microlens array by combining lapping on silicon wafer and rapid surface molding. J. Micromech. Microeng. 2018, 28, 075008. [CrossRef]

21. Ong, N.S.; Fu, Y.Q.; Koh, Y.H. Microlens array produced using hot embossing process. J. Micromech. Microeng. 2002, 60, 365-379. [CrossRef]

22. Zhou, T.F.; Wang, X.B.; Ma, F.B.; Ruan, B.S.; Zhou, J.; Liew, P.J. Microlens array fabrication on WC mold using EDM milling with in situ electrode trimming. Microelectron. Eng. 2019, 103, 3003-3011. [CrossRef]

23. Zhang, L.; Yi, A.Y.; Zhou, W.C. Rapid localized heating of graphene coating on a silicon mold by induction for precision molding of polymer optics. Opt. Lett. 2017, 42, 1369-1372. [CrossRef] [PubMed]

24. Wang, J.; Yi, P.Y.; Deng, Y.J.; Peng, L.F.; Lai, X.M.; Ni, J. Recovery behavior of thermoplastic polymers in micro hot embossing process. J. Mater. Process. Technol. 2017, 243, 205-216. [CrossRef]

25. Li, K.S.; Gong, F.; Xu, G.; Huang, X.F.; Xie, Z.W. Manufacturing of Micro-Lens Array Using Contactless Micro-Embossing with an EDM-Mold. Appl. Sci. 2018, 9, 85. [CrossRef]

26. Liu, J.S.; Jin, X.X.; Tuo, S.; Xu, Z.; Liu, C.; Wang, J.; Chen, L.; Wang, L.D. Hot embossing of polymer nanochannels using PMMA moulds. Microsyst. Technol. 2012, 19, 629-634. [CrossRef]

27. Moore, S.; Song, I.-H.; Gomez, J.; Lek, D.; You, B.H.; Kim, N.W. Experimental study of polymer microlens fabrication using partial-filling hot embossing technique. Microelectron. Eng. 2016, 162, 57-62. [CrossRef] 